\title{
Segmentasi Citra Iris Mata Menggunakan Metode Otsu Thresholding
}

\author{
Muslim Alamsyah \\ muslimalamsyah2@gmail.com
}

\author{
Program Studi Teknik Informatika Universitas Merdeka Pasuruan
}

\begin{abstract}
Iridology or commonly referred to as an iris diagnosis is a medical method that states that each part of the human body can be represented by the area contained in the iris (the colored part of the pupil) and can know someone who has experienced symptoms of the disease. To determine the symptoms of a patient's illness, laboratory tests will generally be carried out, where the test is quite expensive and sometimes causes injury and the results are sometimes long to know, the previous method is able to segment iris images but it is difficult to get accurate iris focus and level value for accuracy because between the sclera, the iris and pupils are still one. Therefore, in this study implementing three-class segmentation using the otsu thresholding method, the otsu method is a good automatic threshold or threshold search method then uses the three-class method by determining the foreground, TBD (To Be Determinand) and background. This method is capable of segmenting iris images well with an accuracy of $99.07 \%$ and Area Under Curve (AUC) value on a $99.07 \%$ relaive operating characteristic (ROC) curve.
\end{abstract}

Intisari- Iridologi atau yang biasa disebut sebagai diagnosis iris adalah suatu metode kedokteran yang menyatakan bahwa tiap bagian pada tubuh manusia dapat direpresentasikan dengan wilayah yang terdapat pada iris mata (bagian yang berwarna pada pupil) dan dapat mengetahui seseorang yang telah mengalami gejala penyakit. Untuk menentukan gejala suatu penyakit yang diderita pasien pada umumnya akan dilakukan tes laboratorium, dimana tes ini cukup mahal dan terkadang menimbulkan luka serta hasilnya pun terkadang lama untuk diketahui, metode sebelumnya mampu melakukan segmentasi citra iris mata tapi sulit untuk pengambilan fokus iris mata yang akurat dan nilai tingkat pada akurasi karena antara sklera, iris mata dan pupil masih jadi satu. Oleh karena itu, pada penelitian ini mengimplementasikan segmentasi tiga kelas menggunakan metode otsu thresholding, metode otsu merupakan metode pencarian ambang batas atau treshold otomatis yang baik kemudian menggunakan metode tiga kelas dengan menentukan foreground, TBD (To Be Determinand) dan background. Metode ini mampu melakukan segmentasi citra iris mata dengan baik yaitu dengan akurasi 99.07 \% dan nilai Area
Under Curve (AUC) pada kurva relaive operating characteristic (ROC) sebesar $99.07 \%$.

Kata Kunci-Citra iris mata, otsu, segmentasi.

\section{PENDAHULUAN}

Iridologi adalah ilmu yang mempelajari pola dan susunan serat pada iris mata [1]. Iridologi atau yang biasa disebut sebagai diagnosis iris adalah suatu metode kedokteran yang menyatakan bahwa tiap bagian pada tubuh dapat direpresentasikan dengan wilayah yang terdapat pada iris mata (bagian yang berwarna pada pupil)[1]. Pada salah satu buku kedokteran, jika terdapat tanda segitiga putih pada daerah mata yang sesuai, maka dapat diketahui bahwa orang tersebut menderita atau pernah menderita penyakit usus buntu (Appendicities) [2]. Namun jika terdapat noda kecil berwarna hitam, maka dapat diindikasikan bahwa penyakit usus buntu tersebut telah disembuhkan melalui operasi Salah satunya adalah tampak di sisi kiri dan sisi kanan mata pattern semangat hidup seseorang baik yang dari pembawaan (ciri keturunan) dan karena lingkungan [2].

Selain itu Selama jangka waktu ratusan tahun, banyak ahli iridologi yang telah mempelajari pola-pola pada mata, dan menghubungkannya dengan problem-problem kesehatan tertentu, kekuatan dan kelemahan fisik seseorang, dan karakter kepribadiannya[1][3]. Melalui pengamatan dan observasi secara empiris, mereka mendapati adanya pola-pola yang beraturan, yang mengindikasikan adanya kelemahan fisik dalam diri seseorang, karena orang-orang yang memiliki pola iri mata sama ternyata mengalami problem kesehatan yang sama. Observasi ini merupakan dasar dari Analisa Iridologi Konstitusional (Constitutional Iridology Analysis), dan kemudian hasilnya disusun dalam sebuah peta mata[4].

Untuk menentukan gejala suatu penyakit yang diderita pasien pada umumnya dilakukan tes di laboratorium, dimana tes ini cukup mahal dan terkadang menimbulkan luka serta hasilnya pun terkadang lama untuk diketahui. Hal ini tentu saja menjadi tantangan tersendiri untuk menemukan metode yang lebih aman dan murah serta cepat untuk menentukan hasilnya. Berdasarkan fakta diatas, maka segmentasi pada citra iris mata merupakan tugas penting untuk dokter dalam mendiagnosa penyakit. Deteksi otomatis atau segmentasi iris mata dari gambar iris mata adalah tahap awal dari proses diagnosis [5]. Untuk mengatasi masalah tersebut Handini Arga 
Damar Rani Endang Supriyati Tutik Khotimah mengusulkan segmentasi citra iris mata menggunakan metode ekstraksi ciri moment invariant, dibantu dengan algoritma K-Means Clustering untuk perhitungan jarak pusat cluster pada citra iris mata[5][6]. Dari hasil citra iris mata yang telah diujikan dapat dikelompokkan menjadi iris mata normal dan iris mata penderita kolesterol tinggi. Dalam penelitian ini tingkat akurasi dari data penelitian adalah sebesar $95 \%$.

Kelemahan metode ini adalah sulit untuk pengambilan fokus iris mata yang akurat karena antara sclera, iris mata dan pupil masih jadi satu. Oleh karena itu pada skripsi ini akan diusulkan sebuah metode tiga kelas segmentasi menggunakan metode otsu thresholding[7].

\section{METODE PENELITIAN}

\section{A. Rancangan Sistem}

Sistem yang dibangun meliputi Langkah-langkah ini di jelaskan dalam gambar flowchart gambar 1 langkah-langkah tersebut adalah deteksi citra iris mata menggunakan otsu thresholding.

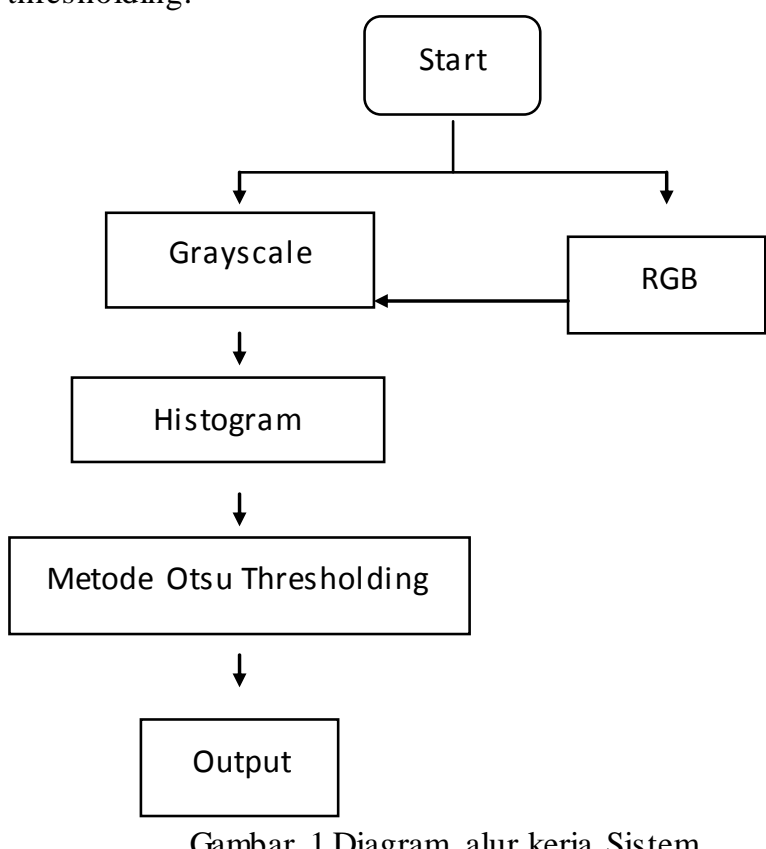

Gambar 1.Diagram alur kerja Sistem

Pada gambar 1 desain sistem secara umum dijelasakan bahwa pertama kita akan menginputkan mata yang kita ambil dari dataset CASIA setelah itu citra mata tersebut akan diproses menggunakan metode otsu thresholding, kemudian akan dihitung rata rata 2 nilai selanjutnya mata tersebut dibagi menjadi tiga kelas yang pertama latar belakang (background) yang kedua TBD (To be determinand) dan yang ketiga latar depan (Foreground).

\section{B. Input Citra Mata}

Pada penelitian ini, data yang digunakan adalah 10 citra mata dari Database CASIA yang diambi dari : http://biometrics.idealtest.org/dbDetailForUser.do? id=4.
Dalam gambar 3.2 terdapat 4 contoh citra mata dari database CASIA yang disediakan.

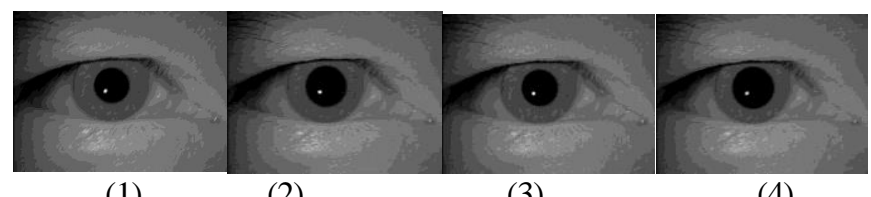

(1) (2)

(3)

(4)

Gambar 2Contoh gambar pada dataset CASIA

\section{Meode Otsu}

Metode Otsu merupakan salah satu metode untuk segmentasi citra digital dengan menggunakan nilai ambang secara otomatis [7], yakni mengubah citra digital warna abuabu menjadi hitam putih berdasarkan perbandingan nilai ambang dengan nilai warna piksel citra digital[8]. Pada penelitian ini data yang saya dapatkan dari citra CASIA sudah berupa grayscale atau abu abu jadi tinggal menghitung nilai ambang atau tresholdnya saja[7][8]. Sebagai contoh citra dari dataset CASIA setelah dilakukan proses segementasi otsu didapatkan $\mathrm{T} 1=83 \mathrm{~T} 2=82 \mathrm{~T} 3=83 \mathrm{~T} 4=82$.

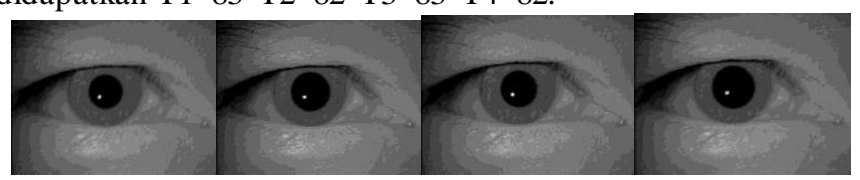

(T1)

(T2)

(T3)

(T4)

Gambar 3 Citra Hasil metode otsu dan otomatis nilai ambang (treshold).

\section{Menghitung Rata-rata 2 Nilai}

Tahap selanjutnya yaitu menghitung rata rata 2 nila Pada tahap ini setelah ketemu nilai ambangnya (Threshold) kita menghitung nilai dari masing masing sebelah kanan dan kiri agar dapat diproses pada tahap selanjutnya sebagai contoh jika T1 atau Tresholnya 96 maka untuk menentukan N1 yaitu dengan car a T1/2 kemudian untuk menentukan N2 yaitu dengan cara $\mathrm{T} 1+\mathrm{N} 1$, seperti contoh gambar dibawah ini

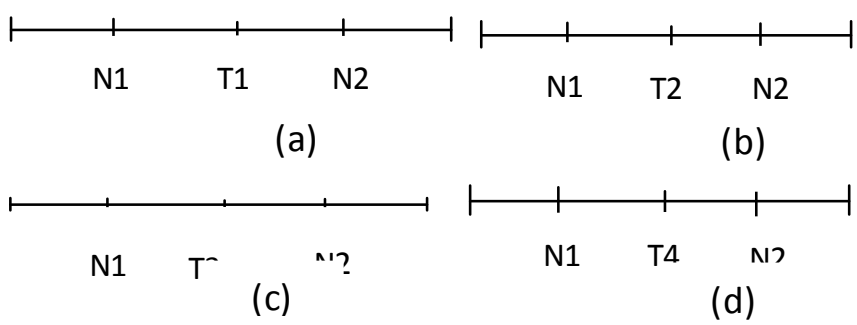

Gambar 4 pencarian nilai rata rata 2 nilai.

Keterangan:

T1=Threshold 1

N1=Nilai Rata rata 1

N2=Nilai Rata rata 2

\section{A. Tahap Uji Coba}

\section{HASIL DAN PEMBAHASAN}

Pada tahap ini, akan dilakukan uji coba terhadap sistem yang telah dikerjakan. Pengukuran kinerja dalam uji coba ini 
menggunakan akurasi, waktu komputasi dan nilai Area Under Curve (AUC) dari kurva Relative Operating Character (ROC). Kurva ROC adalah kurva yang memetakan antara True Positive Rate (TPR) dan False Positive Rate (FPR) dalam sebuah sumbu koordinat yang didapatkan dari hasil proses segmentasi.

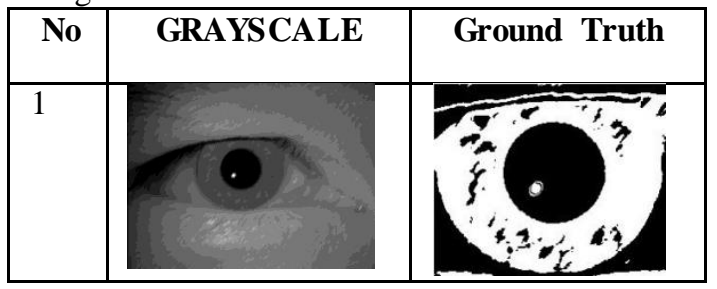

Gambar 5 Citra Iris Mata\&ground truthdari dataset CASIA

Perhitungan kurva ROC dan AUC ditunjukan dengan nilai akurasi dan AUC di presentasikan dalam bentuk prosentase. Semakin tinggi prosentase dari nilai akurasi dan AUC, maka semakin bagus pula hasil segmentasinya.

\section{B. Uji Coba Metode Otsu}

Pada bagian ini dilakukan ujicoba segmentasi otsu dengan input citra iris mata proses ini dilakukan pada 10 citra iris mata tapi yang saya tampilkan hanya 1 citra iris mata.

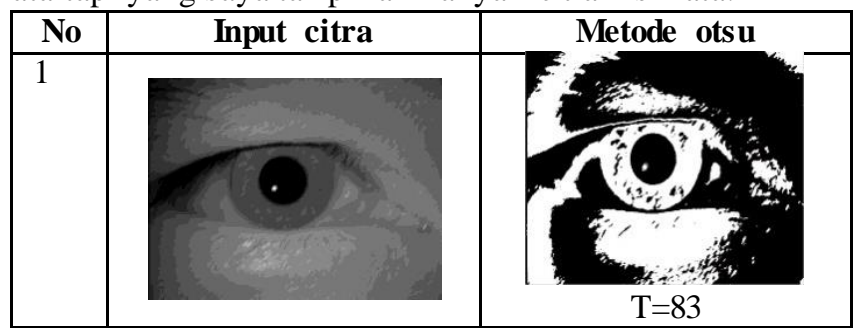

Gambar 6 input citra iris mata (kiri) hasil metode otsu beserta nilai tresholnya (kanan).

\section{Perhitungan akurasi menggunakan ROC}

Dari hasil uji coba mulai input citra pada gambar 6 sampai hasil akhir segmentasi menggunakan metode adaptive kmeans clustering pada gambar 7 selanjutnya dilakukan proses perhitungan akurasi menggunakan ROC dimana Setelah didapatkan hasil akhir citra segmentasi, kemudian dihitung TPR dan FPR dengan cara membandingkannya dengan citra ground truth.

TPR dan FPR yang didapatkan diplotting kedalam kurva ROC seperti tampak pada Gambar 7

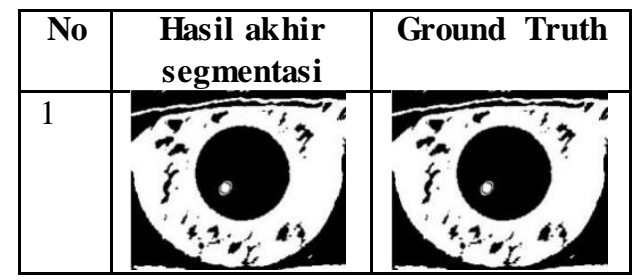

Gambar 7 citra hasil akhir segmentasi(kiri) citra ground truth (kanan)

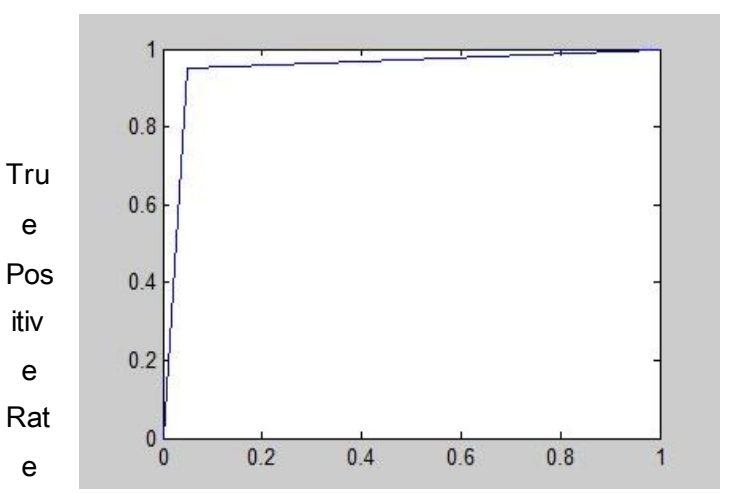

False Positive Rate

Gambar 8 Kurva ROC dari citra hasil segmentasi citra no 1

Pada citra no 1 ini TPR yang didapatkan sebesar 95.27\% dan FPR sebesar 4.94\% dengan nilai AUC 95.16\%. Hasil akurasi dan nilai AUC dari uji coba pada 10 citra iris mata di sajikan dalam Tabel 1.

Tabel. 1 Hasil akurasi dan nilai AUC segmentasi yang diusulkan

\begin{tabular}{|l|l|l|l|l|l|}
\hline Citra & $\begin{array}{l}\text { TPR } \\
(\%)\end{array}$ & $\begin{array}{l}\text { FPR } \\
(\%)\end{array}$ & $\begin{array}{l}\text { Akurasi } \\
(\%)\end{array}$ & $\begin{array}{l}\text { AUC } \\
(\%)\end{array}$ & $\begin{array}{l}\text { Waktu } \\
(\text { Seconds })\end{array}$ \\
\hline No 1 & 95.27 & 4.94 & 95.17 & 95.16 & 0.8 \\
\hline No 2 & 99.04 & 0.90 & 99.07 & 99.06 & 0.6 \\
\hline No 3 & 99.29 & 1.14 & 99.06 & 99.07 & 0.3 \\
\hline No 4 & 97.55 & 1.65 & 98.04 & 97.95 & 0.6 \\
\hline No 5 & 86.04 & 01.24 & 88.59 & 88.40 & 0.6 \\
\hline No 6 & 87.28 & 8.88 & 89.35 & 89.20 & 0.7 \\
\hline No 7 & 85.69 & 7.58 & 89.70 & 89.05 & 0.6 \\
\hline No 8 & 95.42 & 4.65 & 95.39 & 95.38 & 1.4 \\
\hline No 9 & 92.17 & 5.33 & 93.48 & 93.41 & 0.6 \\
\hline No 10 & 94.16 & 6.96 & 93.70 & 93.60 & 0.6 \\
\hline Rata-rata & & & 94.028 & 0.68 \\
\hline
\end{tabular}

\section{Pembahasan Hasil Pengujian}

Pada bagian ini membahas tentang listing interface dan program untuk melakukan segmentasi mengunakan metode otsu dan adaptive k-means clustering seperti gambar di bawah ini: 


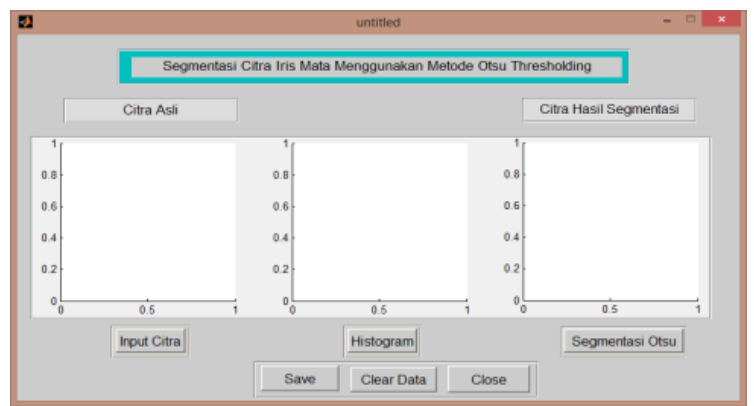

Gambar 9 Tampilan menu utama

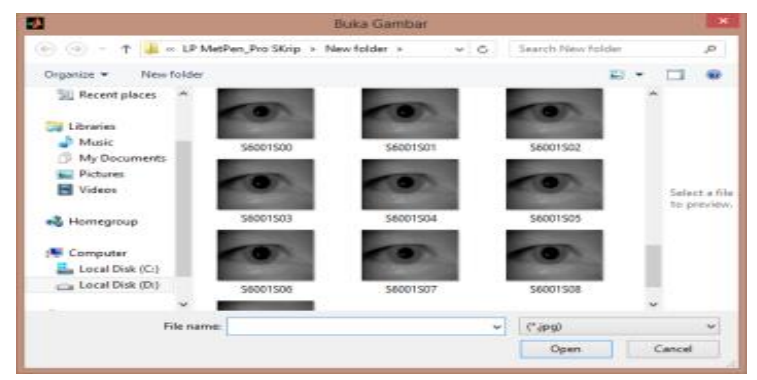

Gambar 10 pemilihan citra iris mata

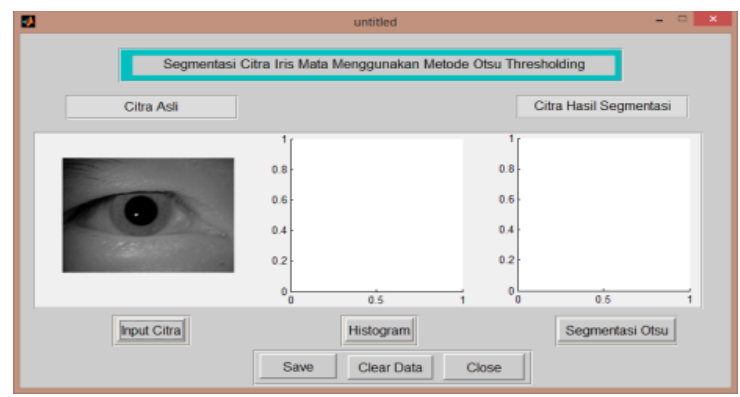

Gambar 11 Tampilan setelah pilih citra iris mata

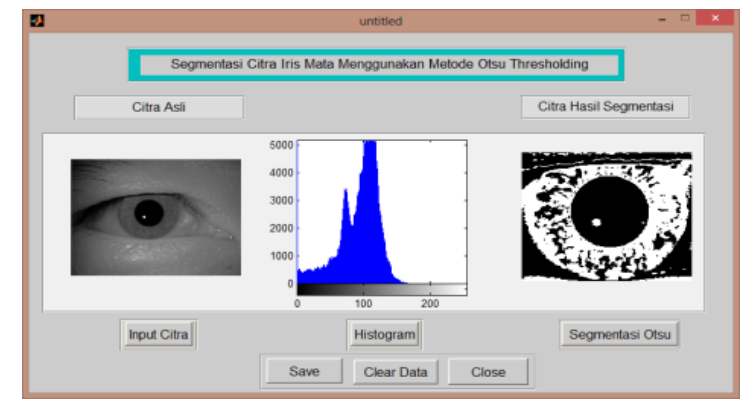

Gambar 12 Tampilan setelah klik tombol Histogram dan segmentasi

\section{KESIMPULAN DAN SARAN}

Pada sub-bab ini dipaparkan kesimpulan yang dapat diambil berdasarkan hasil percobaan dan analisa penelitian yang dilakukan terhadap metode yang diusulkan. Kes impulan metode otsu thresholding mampu melakukan segmentasi citra iris mata dengan baik, yaitu dengan akurasi rata-rata 93,70\% dan Area Under Curve(AUC) rata-rata $94.02 \%$ dengan waktu eksekusi rata-rata 0.6 detik. Dari uji coba sebanyak 10 citra iris mata akurasi terbaik dihasilkan pada citra iris No 02 mencapai 99.07\% dengan waktu eksekusi 0.6 detik. Sedangkan akurasi terendah dihasilkan pada citra iris No 05 mencapai $88.59 \%$ dengan waktu eksekusi 0.6 detik. Hasil analisa citra iris mata bisa dijadikan membantu pengambilan keputusan di bidang kesehatan.

Berdasarkan hasil yang didapatkan dari penelitian ini, ada beberapa saran yang berguna untuk penelitian-penelitian mendatang, perlu adanya penambahan metode perbaikan citra untuk mendapatkan akurasi yang lebih baik lagi. Hasil penelitian ini dapat digunakan sebagai bahan acuan atau rujukan untuk penelitian berikutnya.

\section{DAFTAR PUSTAKA}

[1] A. Razak and H. Lardiman, "Teknik Iridologi dan Kinesiologi Sebagai Alternatif Mengatasi Masalah Stres Disekolah Sebagai Akibat Pemanasan Global," 2013.

[2] M. A. Sander, "Apendisitis Akut: 'Bagaimana Seharusnya dokter Umum dan Perawat Dapat Mengenali Tanda Dan Geala Lebih Dini Penyakit Ini ?"'

[3] R. Yana Simamora, H. Hasan, and M. Rizka, "DETEKSI KELEMAHAN IRIDOLOGI MENGGUNAKAN METODE JARINGAN SYARAF TIRUAN HEBB RULE."

[4] T. K. Handini Arga Damar Rani, Endang Supriyati1, "Dasar-Dasar Analisa Iridologi."

[5] E. A. S. Sahid Nur Afrizall, "Pengenalan Dasar Iris Mata Menggunakan Metode Template Matching Dengan Library Opencv."

[6] A. M.-J. STIMA and U. 2016, "Penerapan Algoritma K-Means Untuk Clustering Penentuan Jurusan Bahasa Mandarin German Dan Prancis," Jurnal.Unma.Ac.Id, 2004.

[7] A. T. R. I. Utami, P. S. Informatika, F. Komunikasi, D. A. N. Informatika, and U. M. Surakarta, "Implementasi metode otsu thresholding untuk segmentasi citra daun," 2017.

[8] I. A. Muwakhid and D. Nurdiyah, "Otsu Method For Image Finish Segmentation With Components of Hue Saturation Value," vol. 15, no. 2, pp. 67-73, 2018. 